\title{
THE APPLICATION OF LARYNGEAL MASK AIRWAY FOR GENERAL ANAESTHESIA IN THE INTERVENTIONAL THERAPY OF CHILDREN WITH ATRIAL SEPTAL DEFECT
}

doi:10.1136/heartjnl-2012-302920ae.2

Shan Reai, Zhan Lifang, Guo Rui, Wang Lifeng, Zhou Aiqin, Zhou Aiqin. First Affiliated Hospital of Gannan Medical College

Objectives To observe the feasibility and validity of remifentanil combined with propofol in general anaesthesia using LMA during paediatric patients undergoing transcatheter atrial septal defect (ASD) closure.

Methods fifty children (ASA I-II) with ASD were randomly divided into two groups: group LMA $(A, n=25)$ and group intubation $(B$, $\mathrm{n}=25)$. LMA was inserted followed by intravenous infusion of propofol $2 \mathrm{mg} / \mathrm{kg}$ and remifentanil $2 \mu \mathrm{g} / \mathrm{kg}$ in group A, while endotracheal intubation was set up following the using of propofol 
$2 \mathrm{mg} / \mathrm{kg}$ and remifentanil $2 \mu \mathrm{g} / \mathrm{kg}$ and cisatracurium besylate $0.1 \mathrm{mg} / \mathrm{kg}$ in group B. Anaesthesia was maintained with intravenous infusion of propofol $4 \mathrm{mg} / \mathrm{kg}$ and remifentanil $0.1 \mu \mathrm{g} / \mathrm{kg} / \mathrm{min}$. The time for operation and recovery from anesthesia, the values of $\mathrm{HR}, \mathrm{MAP}, \mathrm{SPO}_{2}$ was recorded at different terms in two groups (before anesthesia, before and after implantation of LMA or endotracheal tube, before and after the removal of LMA or endotracheal tube). Also, the first successful placement was compared in two groups.

Results There were no significant differences for general information in two groups. such as the time for operation $(64 \pm 5$ vs $68 \pm 6 \mathrm{~min})$ and recovery $(10 \pm 5$ vs $9 \pm 1 \mathrm{~min})$ from anaesthesia, the values of $\mathrm{HR}, \mathrm{MAP}, \mathrm{SPO}_{2}$ before induction, before the LMA (endotracheal) placed, before the removal of the LMA or endotracheal tube $(p>0.05)$. however, the values of MAP $(90.1 \pm 9.2$ vs $115 \pm 11.6 \mathrm{~mm} \mathrm{Hg})(p<0.05) \mathrm{HR}(101 \pm 15$ vs $120 \pm 16$ beats/ $\min )(p<0.05)$ were significantly lower in group $A$ than that in group $B$ at application of endotracheal tube and the values of MAP $(89.0 \pm 8.3$ vs $116 \pm 10.5 \mathrm{~mm} \mathrm{Hg})(p<0.05)$ HR $(99 \pm 11$ vs $119 \pm 13$ beats $/ \mathrm{min})(p<0.05)$ were significantly lower in group A than that in group B extubation points. Postoperative respiratory complications in group B was significantly higher than that in group $\mathrm{A}$.

Conclusions Application of LMA for general anaesthesia in the interventional therapy of children with ASD not only could achieve an effect of haemodynamic-stabilisation, but also reduce postoperative respiratory complications because of its less response of stress. 